\title{
The Chronic Migraineur and Health Services: National Survey Results
}

\author{
Amy Wachholtz ${ }^{1 *}$, Christopher Malone ${ }^{1}$ and Amrita Bhowmick ${ }^{2}$ \\ ${ }^{1}$ Department of Psychiatry, University of Massachusetts Medical School, Worcester, MA 01501, USA \\ ${ }^{2}$ Health Union, Philadelphia, PA-19113, USA
}

\begin{abstract}
Chronic migraine is a costly and highly disabling condition that impacts millions of people in the United States. While chronic migraine is hypothesized to result from more infrequent forms of migraine, the precise mechanism by which this develops is still being researched. This study sought to better characterize the treatment patterns, disorder characteristics, and medical and disability profile of the chronic migraine population using the largest dataset of chronic migraineurs ever collected. The survey was started by 8,359 individuals and 4,787 met the inclusion criteria for diagnosed chronic migraine The number of stressful life events participants experienced due to their migraines related to number of therapies tried $\left(p<0.00\right.$, eta $\left.{ }^{2}=0.215\right)$, depression $\left(p<0.00\right.$, eta $\left.{ }^{2}=0.178\right)$, number of comorbidities $(p<0.00$, eta $\left.^{2}=0.172\right)$, anxiety $\left(p<0.00\right.$, eta $\left.{ }^{2}=0.162\right)$, number of physician visits in the past year $\left(p<0.00\right.$, eta $\left.{ }^{2}=0.103\right)$, and chronic pain levels $\left(p<0.00\right.$, eta $\left.{ }^{2}=0.077\right)$.. The results of this survey suggest that chronic migraineurs may misattribute aspects of psychiatric or medical comorbidities to their chronic migraines. Further, the sample underutilized mental health services and were unsatisfied with their migraine treatments. Providers to chronic migraineurs should ensure that patients are receiving appropriate mental health care in order to alleviate psychological distress as well as to potentially lessen negative life events previously associated with migraine symptoms.
\end{abstract}

Keywords: Chronic migraine; Headache; Mental health services; Psychiatric symptoms

\section{Introduction}

Migraine headache is a prevalent chronic pain condition that afflicts millions of Americans with prevalence estimates ranging between $16.2 \%$ and $22.7 \%$ of adults in the United States [1]. Migraine, however, is not a homogeneous disorder but instead is grossly subdivided into two groups: episodic migraine and chronic migraine.

Chronic migraine is the most severe manifestation of migraine and has been found to impart large costs on individuals and society at large with an overall prevalence rate of about $2 \%$ [2]. Individuals with chronic migraine have been found to be significantly more disabled than episodic migraineurs with a higher degree of impairment to their daily activities $[3,4]$, have significantly worse medical outcomes, and use healthcare resources at a rate of four times that of episodic migraineurs [5]. Further, chronic migraineurs have been found to experience higher indirect costs of their migraines when compared with episodic migraineurs [6]. Chronic migraineurs have been found to experience lower socioeconomic status and greater psychiatric and medical comorbidities when compared to episodic migraineurs [5].

Chronic migraine is currently differentiated from other forms of migraine based almost exclusively on the frequency of migraine symptoms, however, whether chronic migraine is a distinct entity from other forms of migraine is still debated [5]. Some researchers have argued that migraine is a spectrum of illness with chronic migraine as its most extreme form. This viewpoint is supported by biological research showing that chronic migraine is associated with abnormalities in periaqueductal grey matter damage that may develop progressively in milder forms of migraine [7], both forms show similar patterns of cortical excitability between chronic and episodic migraine [8], and abnormal hypothalamic hormone secretion [9]. Chronic migraine may also be a progression of episodic migraine resulting from medication overuse [10] depression [11], and qualitative disability aspects [12,13]. A smaller number of researchers have argued that chronic migraine is far more distinct from episodic migraine than simple migraine frequency due to distinct biomarkers [14], the unique degradation of the endocannabinoid system in chronic migraine [14,15], different sociodemographic and comorbidity profiles [16], and health quality of life and headache related burden [5].

Whether chronic migraine is an extreme manifestation of the experience of episodic migraine, a distinct neurological or biological entity, or a combination of those etiologies is important, however, research has shown that chronic migraine is understudied and that more information is needed about chronic migraineurs [16]. Knowledge of the comorbid disorders experienced by chronic migraineurs, their treatment patterns, and migraine characteristics, can help inform and improve the treatment satisfaction and care of this group. Previous studies which sought to characterize chronic migraineurs have based their findings on relatively small sample sizes drawn from large survey datasets $[17,18]$. Chronic migraine is currently thought to be a preventable disorder, so long as appropriate treatment is identified early enough in the development of the disorder and understanding the experience of chronic migraineurs could have vast implication in reducing the individual and societal burdens of chronic migraine $[5,19,20]$.

The personal and societal costs of chronic migraine as well as the previously reported low treatment satisfaction and adherence rates emphasize the need to understand the treatment patterns of this highly disabled population [17]. This need is emphasized with the observation that chronic migraine may progress from or be the result of treatable conditions. The current study extends the available literature by describing the disability profile, migraine characteristics, stress events, treatment patterns, and comorbidity profile of chronic migraineurs.

*Corresponding author: Amy Wachholtz, PhD, MDiv, MS, Department of Psychiatry, UMass Medical School 55 Lake Ave North, Worcester, MA-01655 USA, Tel: +01 508-334-2164; E-mail: Amy.wachholtz@umassmemorial.org

Received October 17, 2015; Accepted November 03, 2015; Published November 09, 2015

Citation: Wachholtz A, Malone C, Bhowmick A (2015) The Chronic Migraineur and Health Services: National Survey Results. Pain Manage Med 1: 103.

Copyright: (C) 2015 Wachholtz A, et al. This is an open-access article distributed under the terms of the Creative Commons Attribution License, which permits unrestricted use, distribution, and reproduction in any medium, provided the original author and source are credited. 
Citation: Wachholtz A, Malone C, Bhowmick A (2015) The Chronic Migraineur and Health Services: National Survey Results. Pain Manage Med 1: 103.

Page 2 of 8

Significantly, the sample reported in this paper is far larger than in any previously reported chronic migraine research.

\section{Method}

\section{Recruitment}

Participants were recruited from a well-known online migraine headache resource. Adults aged 18 years or older and who currently live in the United States were invited to participate. The presence of chronic migraines was validated through agreement with the statement "Have you ever been diagnosed with chronic migraine by a physician?"

\section{Procedure}

This study was approved by the University of Massachusetts Institutional Review Board. An online survey was presented by a migraine-specific community website over 30 days between July and August 2014. Participants were informed that their participation was voluntary, information would be collected anonymously, the anticipated completion time of the survey, and that they would not receive compensation for participating. No personal identifiers were collected nor solicited from participants. The survey contained questions related to demographic information, migraine history and symptoms, social information, and treatment history and satisfaction. The survey host used embedded cookies to prevent a participant from taking the survey multiple times. The survey employed an adaptive survey methodology. Data was collected by the survey host and stored on secure servers.

\section{Data analysis}

All data analysis was performed using SPSS 22.0. Participant demographics were analyzed using descriptive statistics and Analysis of Variance analyses were used to examine the relationships among survey data.

\section{Results}

\section{Participants}

The survey was started by 8,359 individuals. A total of 3,443 individuals were excluded due to: not consenting to participate $(n=128)$, not living in the United States of America $(n=677)$, less than 18 years old ( $n=69)$, not currently suffering from migraine $(n=57)$, or not diagnosed with chronic migraine $(\mathrm{n}=2,449)$. Of the remaining 4,787 individuals, 3,788 completed it ( $79.1 \%$ completion rate). The mean time to complete the survey was 46.5 minutes ( $\mathrm{SD}=2 \mathrm{hr} 0 \mathrm{~min} 41 \mathrm{sec}$ ). Due to the use of adaptive survey methodology, participants did not answer questions that were not relevant to their experience which resulted in a small variation in the number of responses per question.

\section{Demographics}

The sample was $95.1 \%$ female and over half of the sample (52.6\%) was older than 45 years. Most of the sample (55.8\%) had experienced their first migraine symptoms more than 21 years ago and $70.2 \%$ had been diagnosed with any type of migraine more than 10 years ago. $33.8 \%$ of participants reported being diagnosed with a subtype of migraine and of those individuals, $19.8 \%$ reported being diagnosed with Migraine with Aura (ICD-10 G43.1). Additional demographic information can be found in Table 1.

\section{Comorbid disorders}

Data relating to reported comorbid disorders can be seen in Table 2. Over half of the sample had been diagnosed with depression (59.1\%) and anxiety (56.4\%). The next most frequently reported comorbid

\begin{tabular}{|c|c|c|}
\hline & $\mathbf{N}$ & $\%$ \\
\hline \multicolumn{3}{|l|}{ Gender } \\
\hline Male & 233 & 4.9 \\
\hline Female & 4554 & 95.1 \\
\hline \multicolumn{3}{|c|}{ Age in Years } \\
\hline$<18$ & 69 & $(\mathrm{Excl})$ \\
\hline $18-24$ & 258 & 3.2 \\
\hline $25-34$ & 1054 & 13.2 \\
\hline $35-44$ & 2471 & 30.9 \\
\hline $45-54$ & 2405 & 30.1 \\
\hline $55-64$ & 1416 & 17.7 \\
\hline$>65$ & 390 & 4.8 \\
\hline \multicolumn{3}{|c|}{ First Migraine Symptoms } \\
\hline$<1$ year & 28 & 0.6 \\
\hline $1-5$ years & 343 & 7.3 \\
\hline $6-10$ years & 479 & 10.0 \\
\hline $11-15$ years & 588 & 12.3 \\
\hline $16-20$ years & 672 & 14.0 \\
\hline 21 or more years & 2671 & 55.8 \\
\hline \multicolumn{3}{|c|}{ US Resident } \\
\hline Live in USA or its territories & 7386 & 100 \\
\hline US citizen living abroad & 167 & $(\mathrm{Excl})$ \\
\hline Do not live in USA and not a US citizen & 510 & $(\mathrm{Excl})$ \\
\hline \multicolumn{3}{|c|}{ Ever been diagnosed with chronic migraine by physician } \\
\hline Yes & 4619 & 100 \\
\hline No & 2449 & $(\mathrm{Excl})$ \\
\hline \multicolumn{3}{|c|}{ Diagnosed with another type of migraine at any point } \\
\hline Yes & 1618 & 33.8 \\
\hline No & 1782 & 37.2 \\
\hline Not sure & 1387 & 29.0 \\
\hline \multicolumn{3}{|c|}{ What other type of migraine were you diagnosed with? (ICD-10code) } \\
\hline Episodic Migraine (G43.909) & 892 & 18.6 \\
\hline Migraine without Aura (G43.00) & 655 & 13.7 \\
\hline Menstrual Migraine (G43.82) & 533 & 11.1 \\
\hline Migraine With Aura (G43.1) & 947 & 19.8 \\
\hline Migraine with Typical Aura (G43.109) & 159 & 3.3 \\
\hline Migraine with Brainstem Aura (G43.109) & 96 & 2.0 \\
\hline Hemiplegic Migraine (G43.4) & 243 & 5.1 \\
\hline Retinal Migraine (G43.1) & 200 & 4.2 \\
\hline Abdominal Migraine (G43.D) & 116 & 2.4 \\
\hline
\end{tabular}

Table 1: Patient demographics and disease characteristics.

disorder was chronic pain at $38.2 \%$. $21.1 \%$ of participants reported carrying a diagnosis of chronic fatigue.

\section{Negative life events}

A majority of participants endorsed the following statements describing negative impacts resulting from their migraine: migraines have impacted my work/career $(69.2 \%)$, people don't believe that my migraines are severe (64.3\%), and constantly worried about disappointing people $(53.5 \%)$.

A composite variable named "Negative Life Events Score" was created using items from the survey which examined specific areas of life impacted by participant migraines (Cronbach's alpha $=0.837$ ). The Negative Life Events Score was found to have a mean of 4.92 ( $\mathrm{SD}=3.458$; Possible Range: 0-13; Observed Range: 0-13). The results of questions assessing the impact of chronic migraine on participant's lives can be found in Table 3. The results of the ANOVA analyses identifying relationships among the Negative Life Events Score and a variety of 
Citation: Wachholtz A, Malone C, Bhowmick A (2015) The Chronic Migraineur and Health Services: National Survey Results. Pain Manage Med 1:

\begin{tabular}{|l|l|l|}
\hline Comorbidity & N & (\%) \\
\hline Depression & 2830 & 59.1 \\
\hline Anxiety & 2699 & 56.4 \\
\hline Stroke & 145 & 3.0 \\
\hline Epilepsy & 93 & 1.9 \\
\hline Hypertension & 972 & 20.3 \\
\hline Diabetes & 250 & 5.2 \\
\hline Bipolar Disorder & 253 & 5.3 \\
\hline IBS & 1282 & 26.8 \\
\hline Crohn's Disease & 44 & 0.9 \\
\hline Cardiovascular disease & 87 & 1.8 \\
\hline High Cholesterol & 920 & 19.2 \\
\hline Chronic Pain & 1827 & 38.2 \\
\hline Fibromyalgia & 847 & 17.7 \\
\hline Thyroid Disease & 784 & 16.4 \\
\hline Chronic Fatigue & 1010 & 21.1 \\
\hline Asthma & 763 & 15.9 \\
\hline COPD & 87 & 1.8 \\
\hline Hepatitis & 41 & 0.9 \\
\hline Sleep Disorders & 1447 & 30.2 \\
\hline Rheumatoid Arthritis & 182 & 3.8 \\
\hline Multiple Sclerosis & 21 & 0.4 \\
\hline Autoimmune Disorder & 218 & 4.6 \\
\hline PTSD & 497 & 10.4 \\
\hline OCD & 318 & 6.6 \\
\hline Panic Disorder & 643 & 13.4 \\
\hline Phobia & 185 & 3.9 \\
\hline Borderline-Personality Disorder & 74 & 1.5 \\
\hline Substance Abuse & 136 & 2.8 \\
\hline Pancreatitis & 62 & 1.3 \\
\hline & & \\
\hline
\end{tabular}

Table 2: Comorbid disorders.

\begin{tabular}{|c|c|c|c|}
\hline \multicolumn{2}{|l|}{ Event } & $\mathbf{N}$ & $\%$ \\
\hline \multicolumn{2}{|c|}{ People don't believe that my migraines are severe } & 3080 & 64.3 \\
\hline \multicolumn{2}{|c|}{ I'm constantly worried about disappointing people } & 2559 & 53.5 \\
\hline \multicolumn{2}{|l|}{ Migraines have impacted my work/career } & 3313 & 69.2 \\
\hline \multicolumn{2}{|c|}{ Migraines affect my ability to maintain relationships } & 2036 & 42.5 \\
\hline \multicolumn{2}{|c|}{$\begin{array}{l}\text { Migraines impact my relationship with my child/ } \\
\text { children }\end{array}$} & 1890 & 39.5 \\
\hline \multicolumn{2}{|c|}{ I feel like others blame me for my migraines } & 1757 & 36.7 \\
\hline \multicolumn{2}{|c|}{ Sometimes I blame myself for my migraines } & 1467 & 30.6 \\
\hline \multicolumn{2}{|c|}{$\begin{array}{l}\text { Friends/family/colleagues treat me differently because } \\
\text { of my migraines }\end{array}$} & 1888 & 39.4 \\
\hline \multicolumn{2}{|c|}{ Doctors treat me differently because of my migraines } & 1418 & 29.6 \\
\hline \multicolumn{2}{|c|}{ I feel embarrassed about having migraines } & 1449 & 30.3 \\
\hline \multicolumn{2}{|c|}{ I have lost a job due to migraines } & 1241 & 25.9 \\
\hline \multicolumn{2}{|l|}{ I've lost friends due to my migraines } & 1086 & 22.7 \\
\hline \multicolumn{2}{|c|}{ Migraines contributed to my divorce/separation } & 351 & 7.3 \\
\hline & Mean & SD & Range \\
\hline Negative life events score total score & 4.92 & 3.458 & $0-13$ \\
\hline
\end{tabular}

Table 3: Negative life events.

migraine and medical aspects can be seen in Table 4. The Negative Life Events Score was found to be account for a high degree of variance in depression $\left(\mathrm{p}<0.000\right.$, eta $\left.{ }^{2}=0.1782\right)$, anxiety $\left(\mathrm{p}<0.000\right.$, eta $\left.{ }^{2}=0.1620\right)$, IBS $\left(\mathrm{p}<0.000\right.$, eta $\left.{ }^{2}=0.0379\right)$, chronic pain $\left(\mathrm{p}<0.000\right.$, eta $\left.{ }^{2}=0.0768\right)$, the total number of reported comorbidities $\left(\mathrm{p}<0.000\right.$, eta $\left.{ }^{2}=0.1717\right)$, total number of therapies tried $\left(\mathrm{p}<0.000\right.$, eta $\left.{ }^{2}=0.2147\right)$, and how many times in the past year that the participant had seen their physician $(\mathrm{p}<0.000$, eta $^{2}=0.1034$ ).

\section{Migraine symptoms}

Data relating to migraine symptomology is reported in Tables 5 and 6. Migraine aura was experienced at different rates within the sample with $19.6 \%$ of participants reporting that they never experienced aura with their migraines and a further $43.1 \%$ of participants reporting that they experienced an aura with their migraines "sometimes". Head pain was the most commonly endorsed migraine symptom at $84.5 \%$ and sensitivity to light was the second most endorsed symptom at $80.1 \%$. Just under half of the sample (45.1\%) reported that they currently experience migraine symptoms at a lower frequency than before and of that group only $28.4 \%$ attributed finding the right medical approach for the symptom reduction. $48.6 \%$ of the sample was able to identify a time of day when they are more likely to experience the signs of an impending migraine attack with $55.8 \%$ endorsing the time period of 4:00 am-12:00 pm as the time they are most likely to experience the signs of a migraine attack. Please see Figure 1 for data relating to migraine signs and symptoms by time of day.

\section{Migraine triggers}

$82.9 \%$ of the sample were able to identify at least one trigger for their migraines. Stress was the most common trigger among this sample at $55.8 \%$. The next most commonly endorsed migraine trigger was lack of sleep at $51.9 \% .63 .4 \%$ of participants had taken active steps to avoid triggers for their migraines. Data relating to migraine triggers can be seen in Table 7 .

\section{Migraine treatments}

$87.8 \%$ of the sample reported consulting a physician for treatment of their migraine and of those $89.3 \%$ currently receive treatment from a physician for their migraines. A majority (61.7\%) of participants reported disagreeing with a physician about their migraine treatment at some point with the most highly endorsed reason for disagreement being the participant's previous experience with a treatment that failed (30.5\%). $26.1 \%$ of participants have used a medication that was not prescribed for their migraine to alleviate their symptoms. A majority of participants have avoided the use of a migraine medication because of its side effects $(66.8 \%)$ and $75.1 \%$ of the sample have discontinued use of a medication because of its side effects. Nearly a third of the sample $(30.5 \%)$ currently use four or more prescription medications to treat their migraines and $18.9 \%$ spend $\$ 250$ or more per month on these medications and other care for their migraines. Approximately half $(48.2 \%)$ of the sample used abortive treatment immediately to treat their migraine symptoms; among those who did not use abortive treatment immediately $25.9 \%$ did not want to overuse their medication and $22.7 \%$ wanted to wait to see if the headache became severe because they did not want to waste a limited supply of medication. Nearly half (48.1\%) of the sample "always" incorporates non-pharmacological therapies into their migraine care with dark room being the most used therapy (68.5\%). Data relating to physicians consulted about migraine, medical treatments, and therapies, can be seen in Tables 8-10.

\section{Treatment satisfaction}

Chronic migraineur satisfaction with treatment appeared to depend greatly on the aspect of their care that they were being asked about. A majority (62.1\%) of the sample was either satisfied or very satisfied with their current physician treating their migraine, however, only $29.4 \%$ of the sample was satisfied or very satisfied with their medical treatment for their migraines. $21.9 \%$ of participants were satisfied or very satisfied with their non-pharmacological migraine therapy. Data related to treatment satisfaction can be found in Table 11. 
Citation: Wachholtz A, Malone C, Bhowmick A (2015) The Chronic Migraineur and Health Services: National Survey Results. Pain Manage Med 1:

\begin{tabular}{|c|c|c|c|}
\hline & F(df-btw, df-tot) & $\mathbf{p}$ & $\mathbf{E t a}^{2}$ \\
\hline Depression & $207.337(13,4786)$ & 0.000 & 0.1782 \\
\hline Anxiety & $184.854(13,4786)$ & 0.000 & 0.1620 \\
\hline Stroke & $3.484(13,4786)$ & 0.002 & 0.0036 \\
\hline Epilepsy & $1.861(13,4786)$ & 0.099 & 0.0019 \\
\hline Hypertension & $16.967(13,4786)$ & 0.000 & 0.0174 \\
\hline Diabetes & $5.084(13,4786)$ & 0.000 & 0.0053 \\
\hline Bipolar & $10.781(13,4786)$ & 0.000 & 0.0112 \\
\hline IBS & $37.635(13,4786)$ & 0.000 & 0.0379 \\
\hline Crohn's Disease & $2.505(13,4786)$ & 0.018 & 0.0026 \\
\hline Cardiovascular Disease & $3.049(13,4786)$ & 0.010 & 0.0032 \\
\hline High Cholesterol & $13.037(13,4786)$ & 0.000 & 0.0135 \\
\hline Chronic Pain & $79.545(13,4786)$ & 0.000 & 0.0768 \\
\hline Fibromyalgia & $18.310(13,4786)$ & 0.000 & 0.0188 \\
\hline Thyroid Disease & $14.204(13,4786)$ & 0.000 & 0.0146 \\
\hline Chronic Fatigue & $33.658(13,4786)$ & 0.000 & 0.0340 \\
\hline Asthma & $13.070(13,4786)$ & 0.000 & 0.0135 \\
\hline COPD & $1.992(13,4786)$ & 0.026 & 0.0021 \\
\hline Hepatitis & $1.092(13,4786)$ & 0.273 & 0.0011 \\
\hline Sleep Disorders & $50.430(13,4786)$ & 0.000 & 0.0501 \\
\hline Rheumatoid Arthritis & $5.370(13,4786)$ & 0.003 & 0.0056 \\
\hline Multiple Sclerosis & $2.781(13,4786)$ & 0.846 & 0.0029 \\
\hline Autoimmune Disorder & $4.672(13,4786)$ & 0.000 & 0.0049 \\
\hline PTSD & $22.716(13,4786)$ & 0.000 & 0.0232 \\
\hline OCD & $15.546(13,4786)$ & 0.000 & 0.0150 \\
\hline Panic Disorder & $37.606(13,4786)$ & 0.000 & 0.0378 \\
\hline Phobia & $13.026(13,4786)$ & 0.000 & 0.0134 \\
\hline Borderline Personality Disorder & $2.732(13,4786)$ & 0.000 & 0.0029 \\
\hline Substance Abuse & $8.240(13,4786)$ & 0.000 & 0.0085 \\
\hline Pancreatitis & $1.890(13,4786)$ & 0.115 & 0.0020 \\
\hline Total Number of Reported Comorbidities & $198.156(5,4786)$ & 0.000 & 0.1717 \\
\hline Total Number of Therapies Tried & $261.405(5,47860)$ & 0.000 & 0.2147 \\
\hline Age & $13.679(13,4786)$ & 0.000 & 0.0359 \\
\hline $\begin{array}{l}\text { How long ago did you first start experiencing } \\
\text { migraine symptoms? }\end{array}$ & $1.273(13,4786)$ & 0.221 & 0.0035 \\
\hline $\begin{array}{l}\text { How long ago were you first diagnosed with } \\
\text { migraine? }\end{array}$ & $0.614(13,4786)$ & 0.845 & 0.0017 \\
\hline $\begin{array}{l}\text { How many times in the past year would you } \\
\text { estimate that you have been to see your } \\
\text { physician? }\end{array}$ & $37.933(13,4290)$ & 0.000 & 0.1034 \\
\hline $\begin{array}{l}\text { How many times in the past year have you } \\
\text { been to an emergency room or urgent care } \\
\text { facility for your headache/migraine? }\end{array}$ & $14.592(13,4290)$ & 0.325 & 0.0425 \\
\hline
\end{tabular}

Table 4: ANOVA analysis of negative life events score triad by comorbid disorders

\section{Health care utilization}

Nearly half of the sample (48.6\%) visited their physician five or more times in the past year specifically for their migraines. $43 \%$ of the sample visited an emergency room or urgent care facility at least once in the past year to receive treatment for a migraine, and of that group a third (33.6\%) visited the urgent care facility four or more times. Additional information about emergency health care use can be found in Table 12.

\section{Daily impact}

The sample in this study was found to miss an average of $23.5 \%$ (14.1 days of previous three months; $\mathrm{SD}=26.00$ days) of their productive time in work or school in the past three months because of their migraines. Their productivity at work or school was reduced by half or more in an additional $29.5 \%$ ( 17.7 days; $S D=23.81$ days) in the past three months. They reported missing an average of $15.4(\mathrm{SD}=20.75)$ family, social, or leisure, activities over the past three months due to their headaches.

\begin{tabular}{|c|c|c|}
\hline Symptoms & $\mathbf{N}$ & $\%$ \\
\hline \multicolumn{3}{|c|}{ Do you experience an aura with your migraines? } \\
\hline Always & 544 & 13.1 \\
\hline Most Times & 1000 & 24.2 \\
\hline Some Times & 1784 & 43.1 \\
\hline Never & 809 & 19.6 \\
\hline Head pain & 4045 & 84.5 \\
\hline Sensitivity to light & 3832 & 80.1 \\
\hline Nausea/vomiting & 3384 & 70.7 \\
\hline Diarrhea/constipation & 1342 & 28.0 \\
\hline Diff Concentrating & 3420 & 71.4 \\
\hline Fatigue & 3232 & 67.5 \\
\hline Neck pain & 3076 & 64.3 \\
\hline Dizziness/lightheadedness & 2588 & 54.1 \\
\hline Sensitivity to sound & 3555 & 74.3 \\
\hline Visual Changes & 2453 & 51.2 \\
\hline Weakness & 1984 & 41.4 \\
\hline Mood Changes & 2554 & 53.4 \\
\hline Sensitivity to Smell & 2868 & 59.9 \\
\hline Numbness/tingling & 1522 & 31.8 \\
\hline Vertigo & 1425 & 29.8 \\
\hline Puffy Eyelid & 1067 & 22.3 \\
\hline Food Craving & 1001 & 20.9 \\
\hline Other & 781 & 16.3 \\
\hline
\end{tabular}

Table 5: Migraine symptoms.

\begin{tabular}{|c|c|c|}
\hline Symptoms & $\mathbf{N}$ & $\%$ \\
\hline \multicolumn{3}{|c|}{ Do you experience an aura with your migraines? } \\
\hline Always & 544 & 13.1 \\
\hline Most Times & 1000 & 24.2 \\
\hline Some Times & 1784 & 43.1 \\
\hline Never & 809 & 19.6 \\
\hline Head pain & 4045 & 84.5 \\
\hline Sensitivity to light & 3832 & 80.1 \\
\hline Nausea/vomiting & 3384 & 70.7 \\
\hline Diarrhea/constipation & 1342 & 28.0 \\
\hline Diff Concentrating & 3420 & 71.4 \\
\hline Fatigue & 3232 & 67.5 \\
\hline Neck pain & 3076 & 64.3 \\
\hline Dizziness/lightheadedness & 2588 & 54.1 \\
\hline Sensitivity to sound & 3555 & 74.3 \\
\hline Visual Changes & 2453 & 51.2 \\
\hline Weakness & 1984 & 41.4 \\
\hline Mood Changes & 2554 & 53.4 \\
\hline Sensitivity to Smell & 2868 & 59.9 \\
\hline Numbness/tingling & 1522 & 31.8 \\
\hline Vertigo & 1425 & 29.8 \\
\hline Puffy Eyelid & 1067 & 22.3 \\
\hline Food Craving & 1001 & 20.9 \\
\hline Other & 781 & 16.3 \\
\hline
\end{tabular}

Table 6: Reasons for decreases in migraine symptom frequency

Additional information relating to work and activity impairment due to migraine can be found in Table 13 .

\section{Discussion}

The present study characterized the treatment patterns, stress characteristics, disorder characteristics and disability profile, of the chronic migraine population. The sample of this study was predominantly female, however, this is similar to other studies which have found that migraine, and chronic migraine in particular, are much 
Citation: Wachholtz A, Malone C, Bhowmick A (2015) The Chronic Migraineur and Health Services: National Survey Results. Pain Manage Med 1 :

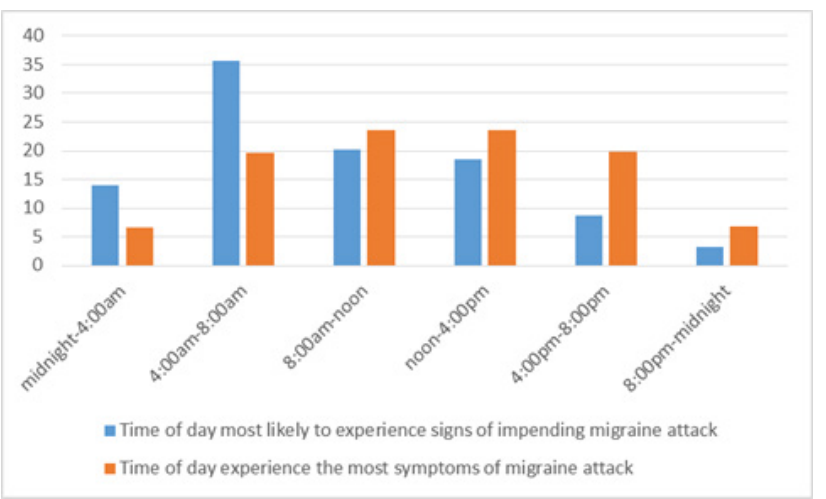

Figure 1: Migraine symptoms and attacks by time of day

\begin{tabular}{|c|c|c|}
\hline Migraine Triggers & N & $\%$ \\
\hline Identified any Triggers & 3416 & 82.9 \\
\hline Stress & 2669 & 55.8 \\
\hline Environment (weather, etc...) & 2870 & 60.0 \\
\hline Lack of Sleep & 2484 & 51.9 \\
\hline Hormones/menstrual cycle & 1792 & 37.4 \\
\hline Certain food drink & 2138 & 44.7 \\
\hline Missing meals & 1884 & 39.4 \\
\hline Certain smell & 2046 & 42.7 \\
\hline Alcohol/drugs & 1235 & 25.8 \\
\hline Physical Activity & 1241 & 25.9 \\
\hline Sexual Activity & 325 & 6.8 \\
\hline Other & 739 & 15.4 \\
\hline Steps taken to avoid triggers & 3033 & 63.4 \\
\hline
\end{tabular}

Table 7: Migraine triggers.

\begin{tabular}{|c|c|c|c|c|}
\hline & \multicolumn{2}{|c|}{$\mathbf{N}$} & \multicolumn{2}{|c|}{$\%$} \\
\hline $\begin{array}{l}\text { Do you currently see a physician for } \\
\text { migraine }\end{array}$ & \multicolumn{2}{|c|}{3749} & \multicolumn{2}{|c|}{89.3} \\
\hline $\begin{array}{l}\text { Ever disagreed with a physician about } \\
\text { migraine treatment }\end{array}$ & \multicolumn{2}{|c|}{2307} & \multicolumn{2}{|c|}{61.7} \\
\hline Meds not strong enough & \multicolumn{2}{|c|}{799} & \multicolumn{2}{|c|}{16.7} \\
\hline Previous experience with treatment failed & \multicolumn{2}{|c|}{1459} & \multicolumn{2}{|c|}{30.5} \\
\hline $\begin{array}{l}\text { Demanded too much time/energy to } \\
\text { follow through }\end{array}$ & \multicolumn{2}{|c|}{182} & \multicolumn{2}{|c|}{3.8} \\
\hline Not covered by insurance & \multicolumn{2}{|c|}{441} & \multicolumn{2}{|c|}{9.2} \\
\hline Other reason & \multicolumn{2}{|c|}{825} & \multicolumn{2}{|c|}{17.2} \\
\hline \multicolumn{5}{|c|}{ Reasons a Physician is not Consulted } \\
\hline Inconvenience/time issues & \multicolumn{2}{|c|}{18} & \multicolumn{2}{|c|}{4.0} \\
\hline Financial/Cost/Insurance issues & \multicolumn{2}{|c|}{162} & \multicolumn{2}{|c|}{35.8} \\
\hline Can't find the right doctor & \multicolumn{2}{|c|}{80} & \multicolumn{2}{|c|}{17.7} \\
\hline It never occurred to me & \multicolumn{2}{|c|}{7} & \multicolumn{2}{|c|}{0.1} \\
\hline Other & \multicolumn{2}{|c|}{185} & \multicolumn{2}{|c|}{40.9} \\
\hline \multirow[t]{2}{*}{ Physicians } & \multicolumn{2}{|c|}{$\begin{array}{l}\text { Physicians Ever } \\
\text { Consulted }\end{array}$} & \multicolumn{2}{|c|}{$\begin{array}{c}\text { Physicians } \\
\text { Currently Treating }\end{array}$} \\
\hline & $\mathrm{N}$ & $\%$ & $\mathrm{~N}$ & $\%$ \\
\hline PCP/internist & 3875 & 80.9 & 1798 & 37.6 \\
\hline Ob/Gyn & 1159 & 24.2 & 122 & 2.5 \\
\hline Neurologist & 3741 & 78.1 & 2274 & 47.5 \\
\hline Headache Specialist & 2003 & 41.8 & 992 & 20.7 \\
\hline Other physician & 814 & 17.0 & 369 & 7.7 \\
\hline
\end{tabular}

Table 8: Physicians consulted about migraine.

more prevalent in the female population [21]. The sample in the study was demographically similar in age to other cross sectional studies of chronic migraineurs [16]. Similar to previous findings, chronic

\begin{tabular}{|c|c|c|}
\hline & $\mathbf{N}$ & $\%$ \\
\hline \multicolumn{3}{|c|}{ How quickly do you initiate abortive treatment to stop and/or to treat symptoms? } \\
\hline Immediately & 2046 & 48.2 \\
\hline Within one hour & 1368 & 32.2 \\
\hline One to two hours & 410 & 9.7 \\
\hline Two to four hours & 157 & 3.7 \\
\hline More than four hours & 37 & 0.9 \\
\hline $\mathrm{N} / \mathrm{A}$ & 227 & 5.3 \\
\hline \multicolumn{3}{|c|}{ Reasons not treated immediately } \\
\hline I need to make sure it is really a migraine & 899 & 18.8 \\
\hline Don't want to waste medication & 1086 & 22.7 \\
\hline I get a lot of false alarms & 114 & 2.4 \\
\hline I don't want to overuse medications & 1239 & 25.9 \\
\hline Other & 330 & 6.9 \\
\hline \multicolumn{3}{|l|}{ Illicit Treatments } \\
\hline $\begin{array}{l}\text { Used a drug that was not prescribed to treat } \\
\text { migraine }\end{array}$ & 1056 & 26.1 \\
\hline Ever used illicit drug to treat migraine & 385 & 9.5 \\
\hline Used marijuana & 806 & 19.9 \\
\hline Used alcohol to treat migraine & 289 & 7.1 \\
\hline Used nicotine/tobacco to treat migraine & 189 & 4.7 \\
\hline Ever avoided a medication because of side effects & 2699 & 66.8 \\
\hline Ever stopped a medication due to side effects & 3034 & 75.1 \\
\hline \multicolumn{3}{|l|}{ Stopped due to: } \\
\hline nausea/vomiting & 1075 & 22.5 \\
\hline stomach ache & 600 & 12.5 \\
\hline rebound headaches & 1378 & 28.8 \\
\hline dizziness & 966 & 20.2 \\
\hline cognitive challenges & 1677 & 35.0 \\
\hline other reason & 1687 & 35.2 \\
\hline Avoided medicine due to cost & 1961 & 48.9 \\
\hline $\begin{array}{l}\text { Withheld medication because you wanted to } \\
\text { "spare" or "save" medication }\end{array}$ & 3055 & 76.1 \\
\hline \multicolumn{3}{|c|}{ How many different prescription products do you currently use to treat migraine } \\
\hline 0 & 295 & 7.4 \\
\hline 1 & 662 & 16.6 \\
\hline 2 & 969 & 24.3 \\
\hline 3 & 839 & 21.1 \\
\hline 4 or more & 1215 & 30.5 \\
\hline
\end{tabular}

How many (if any) prescription products have you EVER USED to TREAT your migraines? By "ever used" we mean that you have ever taken at any point to treat your migraines.

\begin{tabular}{|c|c|c|}
\hline 0 & 23 & 0.6 \\
\hline 1 & 108 & 2.7 \\
\hline 2 & 289 & 7.3 \\
\hline 3 & 415 & 10.4 \\
\hline 4 & 412 & 10.4 \\
\hline 5 & 311 & 7.8 \\
\hline 6 or more & 2422 & 60.9 \\
\hline
\end{tabular}

How much would you estimate that you pay out of pocket monthly for medications and care related to your migraines, including insurance co-pays?

\begin{tabular}{|c|c|c|}
\hline $0-100$ & 1824 & 45.5 \\
\hline $101-250$ & 1135 & 28.3 \\
\hline $251-500$ & 469 & 11.7 \\
\hline$>500$ & 288 & 7.2 \\
\hline not sure & 297 & 7.4 \\
\hline
\end{tabular}

Table 9: Medication and illicit substance use.

migraines were found to impart significant financial, medical, and social costs, on individuals.

Chronic migraineurs were found to experience a high degree of disability related to their condition and a low level of satisfaction with 
Citation: Wachholtz A, Malone C, Bhowmick A (2015) The Chronic Migraineur and Health Services: National Survey Results. Pain Manage Med 1:

\begin{tabular}{|c|c|c|c|c|}
\hline & \multicolumn{2}{|c|}{ Therapies tried } & \multicolumn{2}{|c|}{ Currently Use therapies } \\
\hline & $\mathbf{N}$ & $\%$ & $\mathbf{N}$ & $\%$ \\
\hline Acupuncture & 1386 & 29.0 & 241 & 5.0 \\
\hline Dark room & 3672 & 76.7 & 3277 & 68.5 \\
\hline Diet & 2634 & 55.0 & 1809 & 37.8 \\
\hline hot/cold therapy & 3223 & 67.3 & 2677 & 55.9 \\
\hline Magnesium & 2387 & 49.9 & 1353 & 28.3 \\
\hline Riboflavin/B2 & 1511 & 31.6 & 743 & 15.5 \\
\hline Psychotherapy/pain psychologist & 800 & 16.7 & 245 & 5.1 \\
\hline Biofeedback/EEG/EMG & 932 & 19.5 & 176 & 3.7 \\
\hline Transcranial Magnetic Stimulation & 204 & 4.3 & 70 & 1.5 \\
\hline Light Therapy & 265 & 5.5 & 102 & 2.1 \\
\hline Herbals & 1570 & 32.8 & 616 & 12.9 \\
\hline Movement Therapy-PT/Yoga... & 1024 & 21.4 & 415 & 8.7 \\
\hline Massage & 2488 & 52.0 & 1244 & 26.0 \\
\hline Energy Therapy - Reiki & 365 & 7.6 & 99 & 2.1 \\
\hline Spiritual/religious resources & 744 & 15.5 & 515 & 10.8 \\
\hline other & 807 & 16.9 & 598 & 12.5 \\
\hline \multicolumn{5}{|c|}{ How often are non-medicinal therapies used } \\
\hline & \multicolumn{2}{|c|}{$\mathrm{N}$} & \multicolumn{2}{|c|}{$\%$} \\
\hline never & \multicolumn{2}{|c|}{279} & \multicolumn{2}{|c|}{7.2} \\
\hline rarely & \multicolumn{2}{|c|}{198} & \multicolumn{2}{|c|}{5.1} \\
\hline half the time & \multicolumn{2}{|c|}{501} & \multicolumn{2}{|c|}{13.0} \\
\hline most times & \multicolumn{2}{|c|}{1024} & \multicolumn{2}{|c|}{26.5} \\
\hline always & \multicolumn{2}{|c|}{1855} & \multicolumn{2}{|c|}{48.1} \\
\hline
\end{tabular}

Table 10: Non-prescription therapies.

\begin{tabular}{|c|c|c|c|c|c|c|}
\hline & \multicolumn{2}{|c|}{ Treatment Satisfaction } & \multicolumn{2}{|c|}{$\begin{array}{l}\text { How satisfied are you with your current non- } \\
\text { prescription therapies for migraine }\end{array}$} & \multicolumn{2}{|c|}{ How satisfied with current physician } \\
\hline & $\mathbf{N}$ & $\%$ & $\mathbf{N}$ & $\%$ & $\mathbf{N}$ & $\%$ \\
\hline Extremely Satisfied & 182 & 4.5 & 101 & 2.6 & 1064 & 28.5 \\
\hline Satisfied & 1010 & 24.9 & 757 & 19.3 & 1256 & 33.6 \\
\hline Neutral & 1426 & 35.2 & 1777 & 45.4 & 947 & 25.3 \\
\hline Dissatisfied & 878 & 21.7 & 820 & 21.0 & 333 & 8.9 \\
\hline Extremely Dissatisfied & 523 & 12.9 & 328 & 8.4 & 138 & 3.7 \\
\hline Not applicable & 35 & 0.9 & 130 & 3.3 & 450 & 9.7 \\
\hline
\end{tabular}

Table 11: Treatment satisfaction.

How many times in the past year would you estimate that you have been to see your physician (not counting any emergency room visits) regarding your headache/ migraine?

\begin{tabular}{|c|c|c|}
\hline & $\mathrm{N}$ & $\%$ \\
\hline 1 or less & 549 & 12.8 \\
\hline 2 & 493 & 11.5 \\
\hline 3 & 495 & 11.5 \\
\hline 4 & 668 & 15.6 \\
\hline 5 or more & 2068 & 48.6 \\
\hline \multicolumn{3}{|c|}{ Have you been to an emergency room or urgent care facility in the past year for your headache/migraine? } \\
\hline & $\mathrm{N}$ & $\%$ \\
\hline Yes & 2057 & 43.0 \\
\hline \multicolumn{3}{|c|}{ How many times in the past year have you been to an emergency room or urgent care facility for your headache/migraine? } \\
\hline & $\mathrm{N}$ & $\%$ \\
\hline 1 & 547 & 26.6 \\
\hline 2 & 495 & 24.1 \\
\hline 3 & 321 & 15.6 \\
\hline 4 or more & 690 & 33.6 \\
\hline
\end{tabular}

Table 12: Emergency healthcare.

regard to their medical and therapeutic approaches despite typically being satisfied with their treating physician. This is significant in suggesting that while chronic migraineurs have typically tried multiple treatments without improvement, they are typically still engaged seeking treatment and have generally not resorted to self-medication. Future research should explore the factors that contribute to the resiliency of chronic migraineurs in the context of high medical disability and chronic pain. 
Despite being a cross-sectional study, the data presented in this article suggests that chronic migraine should not be viewed as simply a progression from episodic migraine based on easily quantified factors, such as comorbid medical or psychiatric factors. Previous research has identified depression as a causal factor in the progression of episodic migraine to chronic migraine [11]. The sample in this study had been diagnosed with depression at a lower rate than would have been expected if depression was truly a principal precipitating factor in the chronification of migraine. Similarly, chronic medication overuse has been implicated as a causal factor in the chronification of migraine but the sample in this study was found to be both knowledgeable and cautious in their use of abortive migraine medication. It is possible that the participants in this study were made aware of the dangers of medication overuse only after the development of chronic migraine; providers should emphasize the dangers of medication overuse in the context of the chronification of migraine whenever treating patients with episodic migraine. Additionally, a high proportion of the participants in this study who reported a symptom decrease were ignorant of the cause of the reduction in symptoms, attesting to the heterogeneity of the disorder.

An interesting pattern emerged when migraine symptoms were examined by time of day with many participants endorsing the period between 4:00 am-8:00 am as the period they were most likely to experience the signs of an impending migraine attack. This suggests that the sleep/wake cycle of a migraineur may be clinically significant in the chronification of migraine, however, it may also be that these chronic migraineurs have been misdiagnosed and are instead experiencing hypoxic migraines resulting from undiagnosed or untreated sleep apnea.

Similar to previous findings, the chronic migraineurs in this study endorsed a high degree of negative life events resulting from their migraine with the majority of negative events being experienced as social impairments [22,23]. Significantly, the Negative Life Events Score was found to be highly correlated with a large variety of comorbid disorders but was not significantly correlated with the length of time since first migraine symptoms or the length of time since migraine diagnosis. This suggests that chronic migraine is not a static linear progression from episodic migraine and that it is possible that participants in this sample may attribute impairments due to other comorbid psychiatric and medical disorders to their migraine. In light of the finding that the most common comorbid disorders in this sample could be somaticized psychiatric disorders (i.e. depression and anxiety), it is possible that more serious symptoms of psychiatric disorders are being masked by overlapping migraine symptoms, leading to an underestimate of true psychiatric impairment. Further, the sample in this study utilized mental health services in a far lower degree than would have been expected given their reported psychiatric comorbidities. The sample in this study also reported missing a large number of days of professional, educational, and leisure activities in the previous three months due to their migraine. If even a portion of these days can be attributed to psychological symptoms instead of pure migraine symptoms then it is likely that these participants could be experiencing the symptoms of major mental illness, such as major depressive disorder, further emphasizing the need for psychological intervention.

\section{Limitations}

There are some limitations to the present study. Participants were recruited through an online portal so issues such as selfidentification and self-selection cannot be discounted, however, this is common in migraine literature where surveys are the most prevalent method [17]. As discussed previously, the gender composition of this sample was slightly more female than samples in other large chronic migraine samples [19]. The lack of information collected relating to participant race, education, or socioeconomic status may also limit the generalizability of this study.

\section{Conclusion}

The present study extends the literature characterizing the treatment patterns, stress characteristics, disorder characteristics and disability profile, of the chronic migraine population in the largest sample yet collected. Chronic migraineurs were found to experience significant impairment to their personal, professional, and social functioning. Psychological comorbidities were suggested to exert a magnifying effect on the negative experiences of migraine headache with a corresponding underutilization of mental health interventions in this sample. Chronic migraineurs were found to have tried many different treatments but are, overall, unsatisfied with their efficacy while simultaneously being satisfied with their treatment provider. Future research should explore the role of psychiatric distress and somatization as a causal factor in the chronification of migraine. Current providers of chronic migraineurs should emphasize the importance of psychological care in the context of a chronic illness to both address the common psychological component as well as to potentially lessen the impact of chronic migraine on daily life.

\section{Acknowledgement}

Funding for this research was partially provided by the National Institutes of Health. Grant no: K23DA030397 (awarded to AW)

\section{References}

1. Smitherman TA, Burch R, Sheikh H, Loder E (2013) The prevalence, impact, and treatment of migraine and severe headaches in the United States: a review of statistics from national surveillance studies. Headache 53: 427-436.

2. Vargas BB, Dodick DW (2009) The face of chronic migraine: epidemiology demographics, and treatment strategies. Neurol Clin 27: 467-479.

3. Bigal ME, Rapoport AM, Lipton RB, Tepper SJ, Sheftell FD (2003) Assessmen of migraine disability using the migraine disability assessment (MIDAS) questionnaire: a comparison of chronic migraine with episodic migraine. Headache 43: 336-342.

4. Katsarava Z, Buse DC, Manack AN, Lipton RB (2012) Defining the differences between episodic migraine and chronic migraine. Curr Pain Headache Rep 16: 86-92.

5. Manack AN, Buse DC, Lipton RB (2011) Chronic migraine: epidemiology and disease burden. Curr Pain Headache Rep 15: 70-78.

6. Stewart WF, Wood GC, ManackA, Varon SF, Buse DC, et al. (2010) Employment and work impact of chronic migraine and episodic migraine. J Occup Environ Med 52: 8-14.

7. Aurora SK (2009) Spectrum of illness: understanding biological patterns and relationships in chronic migraine. Neurology 72: S8-13.

8. Aurora SK, Barrodale P, Chronicle EP, Mulleners WM (2005) Cortical inhibition is reduced in chronic and episodic migraine and demonstrates a spectrum of illness. Headache 45: 546-552.

9. Peres MF, Sanchez del Rio M, Seabra ML, Tufik S, Abucham J, et al. (2001) Hypothalamic involvement in chronic migraine. J Neurol Neurosurg Psychiatry 71: 747-751.

10. Obermann M, Gizewski ER, Limmroth V, Diener HC, Katsarava Z (2006) Symptomatic migraine and pontine vascular malformation: evidence for a key role of the brainstem in the pathophysiology of chronic migraine. Cephalalgia 26: 763-766.

11. Ashina S, Serrano D, Lipton RB, Maizels M, Manack AN, et al. (2012) Depression and risk of transformation of episodic to chronic migraine. $J$ Headache Pain 13: 615-624.

12. D'Amico D, Grazzi L, Usai S, Rigamonti A, Curone M, et al. (2005) Disability pattern in chronic migraine with medication overuse: a comparison with migraine without aura. Headache 45: 553-560.

13. http://ihs-classification.org/en/02_klassifikation/02_teil1/01.05.01_migraine. html. 
Citation: Wachholtz A, Malone C, Bhowmick A (2015) The Chronic Migraineur and Health Services: National Survey Results. Pain Manage Med 1: 103.

14. Cernuda-Morollón E, Larrosa D, Ramón C, Vega J, Martínez-Camblor P, et al. (2013) Interictal increase of CGRP levels in peripheral blood as a biomarker for chronic migraine. Neurology 81: 1191-1196.

15. Cupini LM, Costa C, Sarchielli P, Bari M, Battista N, et al. (2008) Degradation of endocannabinoids in chronic migraine and medication overuse headache. Neurobiol Dis 30: 186-189.

16. Buse DC, Manack A, Serrano D, Turkel C, Lipton RB (2010) Sociodemographic and comorbidity profiles of chronic migraine and episodic migraine sufferers. Neurol Neurosurg Psychiatry 81: 428-432.

17. Bigal ME, Serrano D, Reed M, Lipton RB (2008) Chronic migraine in the population: burden, diagnosis, and satisfaction with treatment. Neurology 71 559-566

18. Bigal ME, Borucho S, Serrano D, Lipton RB (2009) The acute treatment of episodic and chronic migraine in the USA. Cephalalgia 29: 891-897.
19. Buse DC, Manack AN, Fanning KM, Serrano D, Reed ML, et al. (2012) Chronic migraine prevalence, disability, and sociodemographic factors: results from the American Migraine Prevalence and Prevention Study. Headache 52: 14561470.

20. Lipton RB1 (2009) Tracing transformation: chronic migraine classification, progression, and epidemiology. Neurology 72: S3-7.

21. Buse DC, Manack AN, Fanning KM, Serrano D, Reed ML, et al. (2012) Chronic migraine prevalence, disability, and sociodemographic factors: results from the American Migraine Prevalence and Prevention Study. Headache 52: 14561470.

22. Malone CD, Bhowmick A, Wachholtz AB (2015) Migraine: treatments comorbidities, and quality of life, in the USA. J Pain Res 8: 537-547.

23. http://migraine.com. 